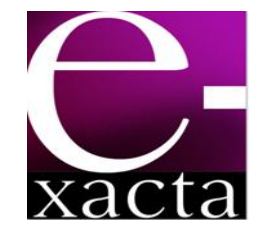

ISSN: 1984-3151

\title{
DióXIDO dE ESTANHO MOdIFICADO COM FERRO: Catalisadores para Reação de OXidação de RODAMINA B
}

\author{
Dioxide TIN MOdified With IRON: CATALYST FOR REACTION
} OXIDATION RHODAMINE B

\author{
Gian Carlo de Oliveira Boscolo'; Jonas Leal Neto ${ }^{2}$ \\ 1 Mestre em Agroquímica/Química,UFLA, 2015. Universidade \\ Federal de Lavras - UFLA. Lavras, MG \\ gianboscolo@ig.com.br. \\ 2 Doutor em Ciências- Química Inorgânica. UFMG, 2006. \\ Professor da Universidade Federal de Lavras - UFLA. \\ Lavras, MG. neto.j|@dqi.ufla.br.
}

Recebido em: 10/03/2016 - Aprovado em: 06/05/2016 - Disponibilizado em: 31/05/2016

\begin{abstract}
RESUMO: Os descartes de efluentes industriais têm se tornado um grave problema ambiental, devido à sua composição diversificada e à toxicidade que dificulta sua remoção pelos processos convencionais de tratamento, em particular os rejeitos da indústria têxtil que, além de tóxicos, são caracterizados pela intensa coloração. Visando à remoção destes corantes, realizou-se, neste trabalho, uma dopagem do dióxido de estanho com 0,10\%, $0,15 \%$ e $0,20 \%$ de ferro, com o objetivo de avaliar o potencial catalítico do óxido puro, em relação ao material dopado, na remoção de cor de soluções contendo o corante orgânico rodamina $B$ como molécula modelo. Os materiais sintetizados foram caracterizados por meio de MEV-EDS, difração de raios $X$, fluorescência de raios $X e$ reflectância difusa. As soluções contendo a molécula modelo foram acondicionadas em um fotorreator com iluminação ultravioleta e monitoradas em UV-Vis, a cada 30 minutos. Para verificar a condição ótima da reação, foram testadas quantidades diferentes de catalisadores, peróxido e concentrações de rodamina $B$. Foi observado que os materiais contendo $0,10 \%$ e $0,15 \%$ de ferro obtiveram resultados mais satisfatórios, removendo, aproximadamente, $60 \%$ da cor em 120 minutos de reação.
\end{abstract}

PALAVRAS-CHAVE: Óxidos metálicos. Processos oxidativos avançados. Catálise heterogênea.

ABSTRACT: The discharges of industrial waste have become a serious environmental problem because of its diverse composition and toxicity which hampers the removal by conventional treatment processes, in particular the waste from the textile industry that besides toxic, they are characterized by intense staining. Aimed at removing these dyes, was held in this study, a tin dioxide doping with $0.10 \%, 0.15 \%$ and $0.20 \%$ of iron in order to evaluate the catalytic potential of pure oxide, compared to doped materials, in the removal of color solutions containing the organic dye rhodamine $B$ as template molecule. The synthesized materials were characterized by SEM-EDS, $X$ ray diffraction, $X$-ray fluorescence and diffuse reflectance. The solutions containing the template molecule were placed in a photoreactor with ultraviolet light and monitored by UV-Vis, every 30 minutes. To check the optimal reaction condition, were tested different amounts of catalysts, concentrations of peroxide and rhodamine $B$. It was observed that the material containing $0.10 \%$ to $0.15 \%$ iron obtained more satisfactory results, removing, approximately $60 \%$ of the color in 120 minutes of reaction.

KEYWORDS: Metal Oxides. Advanced Oxidation Processes. Heterogeneous Catalysis. 


\section{INTRODUÇÃo}

Existe uma enorme variedade de problemas relacionados às águas superficiais. $O$ desenvolvimento industrial e residencial não sustentável está diretamente ligado ao aumento do descarte de poluentes, o que tem gerado grandes problemas ambientais. No entanto, a preocupação em relação aos descartes da indústria é mais relevante, visto que as substâncias, na sua maioria, são tóxicas e de difícil degradação (TEIXEIRA et al., 2012).

A poluição ambiental por efluentes de origem industrial tem aumentado gradativamente nas últimas décadas, gerando problemas sociais e ambientais. Os resíduos apresentam, em geral, composição diversificada, além de poluentes tóxicos e/ou resistentes aos sistemas convencionais de tratamento (coagulação/floculação, adsorção com carvão ativado, precipitação, degradação biológica etc.) (SALGADO et al., 2009).

Grande parte do problema envolve o descarte de corantes. Segundo Fu e Viraraghavan (2001), somente na área têxtil existem acima de 100.000 corantes comerciais disponíveis, com produção acima de $7 \times 10^{5}$ toneladas por ano, no mundo e, desse total, 26.500 toneladas somente no Brasil.

Segundo Khaled et al. (2009), estima-se que de 15\% a $50 \%$ da carga de corantes podem ser perdidas nas etapas de tingimento e lavagem, o que torna evidente a necessidade de sistemas adequados de tratamento.

Além dos corantes, a indústria têxtil utiliza uma grande quantidade de água em seus processos, o que gera, consequentemente, grande quantidade de efluentes das mais diversas características.

Um método bastante utilizado para o tratamento de poluentes é a fotocatálise heterogênea, a qual se destaca pela simplicidade de aplicação e a possibilidade de promover uma degradação mais efetiva do poluente a ser tratado.
O processo fotocatalítico baseia-se na iluminação de um material semicondutor com radiação de energia maior ou igual à sua energia de band gap, energia necessária para excitar um elétron da banda de valência (BV) e promovê-lo para a banda de condução (BC). Com isso, ocorre a separação de cargas formando o par lacuna/elétron ( $\mathrm{h}+\mathrm{e}-\mathrm{e})$ com potencial de oxidação e/ou redução suficiente para a degradação dos compostos orgânicos (OLIVEIRA et al., 2013).

Uma classe de materiais que vem recebendo atenção especial em função de suas vastas propriedades químicas e eletrônicas é a dos óxidos metálicos. Em aplicações químicas, os óxidos metálicos são utilizados como suporte para catalisadores metálicos, podendo, frequentemente, exibir atividade catalítica.

O dióxido de estanho apresenta energia de band gap da ordem de 3,6 eV, o que Ihe confere um elevado número de aplicações e boa capacidade para agregar dopantes. Além disso, soma-se a vasta abundância do metal em nosso país, o que faz com que seu preço seja bastante acessível (DNPM).

Neste trabalho, utilizou-se o dióxido de estanho $\left(\mathrm{SnO}_{2}\right)$ dopado com ferro, com o objetivo de avaliar a melhora na atividade fotocatalítica após a entrada do metal dopante na estrutura do óxido, avaliando a remoção de cor de soluções contendo o corante orgânico rodamina $\mathrm{B}$.

\section{MATERIAIS e MÉtodos}

\subsection{SínTESE dos MATERIAIS}

A metodologia utilizada para a obtenção dos óxidos foi descrita por Cornell e Schwertmman (2003).

Os compostos de $\mathrm{Fe}$ (III) foram preparados a partir das soluções aquosas de nitrato de ferro III $\left[\mathrm{Fe}\left(\mathrm{NO}_{3}\right)_{3} .9 \mathrm{H}_{2} \mathrm{O}\right]$ - marca VETEC - e cloreto de estanho II [ $\left.\mathrm{SnCl}_{2} .2 \mathrm{H}_{2} \mathrm{O}\right]$ - marca VETEC, pelo método 
de coprecipitação com hidróxido de sódio. Para a precipitação usou-se uma solução de hidróxido de sódio - marca VETEC - 5 mol.L-1.

$\mathrm{Na}$ Figura 1 estão ilustrados os procedimentos utilizados na síntese dos materiais.

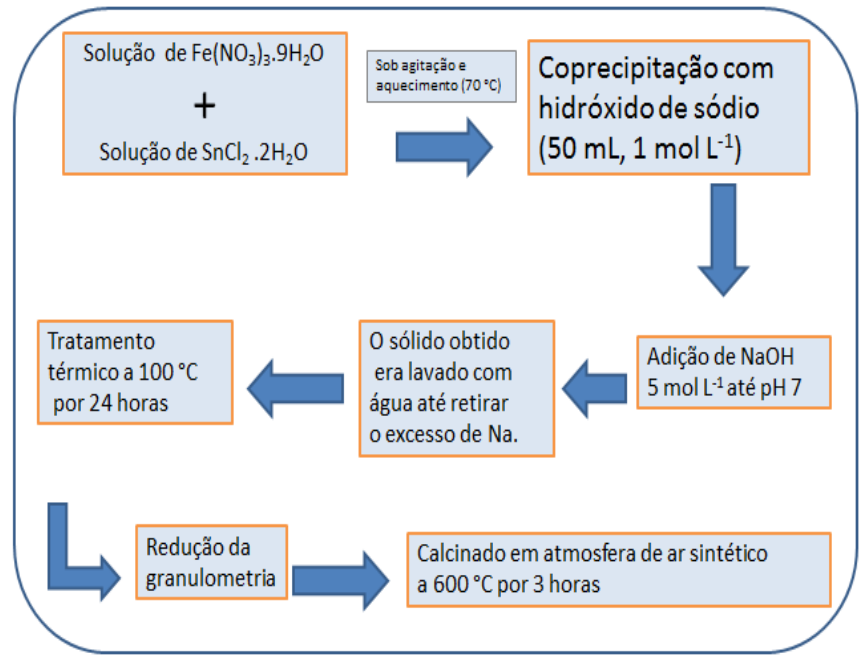

Figura 1 - Fluxograma representativo do processo utilizado na síntese dos compostos

Fonte - Próprio autor

Para o material puro utilizaram-se $10,0 \mathrm{~g}$ de cloreto de estanho II, e para o material dopado a síntese foi feita em triplicata, partindo-se de $8,9958 \mathrm{~g}$ de cloreto de estanho II e 1,7897 $\mathrm{g}$ de nitrato de ferro III, valores calculados em relação à proporção, em quantidade de matéria, de 2,5\% de ferro em relação ao $\mathrm{SnO}_{2}$, obtendo-se ao final, materiais modificados com as concentrações de 0,$10 ; 0,15$ e $0,20 \%$ de ferro em relação do $\mathrm{SnO}_{2}$.

Os sólidos foram obtidos por coprecipitação com $\mathrm{NaOH} 5$ mol.L-1 e, após serem lavados para remoção de sódio, foram secos em estufa. A granulometria do material foi reduzida e procedeu-se a calcinação dos materiais em atmosfera de ar sintético.

Para as análises por fluorescência de raios $X$, as amostras foram trituradas e tamisadas em malha de nylon de $150 \mu \mathrm{m}$. Depois foram pesados $50 \mathrm{mg} \mathrm{da}$ amostra em tubos falcon, nos quais foram adicionados $2,5 \mathrm{~mL}$ de solução de Triton $\AA \mathrm{X}-100$ a $5 \% \mathrm{v} / \mathrm{v}$ em água ultrapura e 0,5 mL de solução de Ga $1000 \mathrm{mg} \cdot \mathrm{kg}^{-1}$, resultando em concentração final de $\mathrm{Ga}$ igual a $166,667 \mathrm{mg} \cdot \mathrm{kg}^{-1}$. Cada tubo foi agitado em agitador tipo vortex, obtendo-se, assim, uma suspensão homogênea. Imediatamente após a agitação, foram pipetados $10 \mu \mathrm{L}$ da suspensão a qual foi gotejada no centro de um porta-amostra de quartzo, devidamente higienizado. Para facilitar a formação de uma película fina de cerca de $10 \mathrm{~mm}$ de espessura da amostra, previamente uma solução de silicone em isopropanol foi gotejado no porta-amostra. Cada amostra foi lida em triplicata durante 300 segundos.

O aparelho TXRF S2 Picofox ${ }^{\mathrm{TM}}$ é conectado ao software Spectra. Alguns parâmetros técnicos utilizado são: tensão $20 \mathrm{kV}$; corrente 0,602 mA; Anodo Mo; monocromador 17.500 multicamadas; detector de $\mathrm{Si}$; fonte de raios- $X$ tubo de cerâmica metal, resfriado a ar, MCB50-0.7G; alvo de Mo com filamento de W; janela de Be $100 \mu \mathrm{m}$; energia 17,5 keV.

As difrações de raios $\mathrm{X}$ em método do pó (DRX) foram realizadas em um equipamento RIGAKU modelo GEIGERFLEX, munido de tubo de cobre e monocromador de grafite. As análises foram obtidas a temperatura ambiente, utilizando radiação $\mathrm{Ka}$ do $\mathrm{Cu}(\lambda$ $=1,54056 \AA \stackrel{\circ}{)}$, corrente de $35 \mathrm{~mA}$ de $40 \mathrm{kV}$. A velocidade de varredura foi de $1^{\circ} \mathrm{C} \cdot \mathrm{min}^{-1}$, usando a contagem de tempo de cinco segundos por incremento e empregando-se uma variação angular de $20^{\circ}$ a $80^{\circ}$. Para efeito de calibração, foi usado cloreto de sódio $(\mathrm{NaCl})$ como padrão interno.

A morfologia dos materiais foi analisada por microscopia eletrônica de varredura (MEV) em um microscópio eletrônico de varredura LEO EVO 40XVP (Carl Zeiss SMT), usando uma tensão de $25 \mathrm{kV}$. As amostras foram montadas em suportes de alumínio (stubs), com uma fita de carbono dupla face (para fixação das amostras) colocada sobre uma película de papel alumínio, cobertas com uma camada delgada de

e-xacta, Belo Horizonte, v. 9, n. 1, p. 79-87. (2016). Editora UniBH doi: 10.18674/exacta.v9i1.1770 
ouro de poucos $\AA$ de espessura em um evaporador Balzers SCD 050.

A fim de se obter os valores de band gap para os fotocatalisadores, os materiais preparados foram analisados por reflectância difusa no ultravioletavisível (UV-vis). Os espectros de reflectância difusa foram obtidos usando um equipamento Varian Cary 5, equipado com acessório para reflectância difusa.

\subsection{Testes CATALÍticos}

\subsubsection{Decomposição de Peróxido de HIDROGÊNIO ( $\left.\mathrm{H}_{2} \mathrm{O}_{2}\right)$}

O potencial catalítico dos materiais foi analisado por meio da degradação do peróxido de hidrogênio $\left(\mathrm{H}_{2} \mathrm{O}_{2}\right)$. Nesse processo foram utilizados $2,0 \mathrm{~mL}$ de solução $50 \%$ de peróxido de hidrogênio $\left(\mathrm{H}_{2} \mathrm{O}_{2}\right) ; 30 \mathrm{mg}$ de catalisador e 5,0 $\mathrm{mL}$ de água deionizada, sob agitação magnética constante, em temperatura ambiente. Em um segundo momento, a água foi substituída pela solução de corante orgânico rodamina B.

\subsubsection{Testes Fotocatalíticos}

Os testes foram realizados em diferentes concentrações do corante orgânico rodamina $B(5,10$, 20, 40 e 80 ppm) e em diferentes quantidades de peróxido de hidrogênio $(0,2 ; 0,01$ e $0,001 \mathrm{~mL})$, objetivando a otimização do processo e, dessa forma, auxiliando na definição dos parâmetros analíticos.

\section{Resultados e Discussão}

\subsection{FLUORESCÊNCIA DE RAIOS X}

Os testes com fluorescência de raios $\mathrm{X}$ foram realizados com os objetivos de demonstrar a presença e determinar as quantidades de ferro presente nos materiais. As amostras foram analisadas em triplicata e as médias dos resultados esperados e obtidos estão mostradas na Tabela 1.

Os resultados demonstraram a presença de ferro nos compostos, porém, em um percentual abaixo do esperado.

Tabela 1

Concentração em mg. $\mathrm{L}^{-1}$ das análises realizadas em fluorescência de raios $X$

\begin{tabular}{|c|c|c|c|}
\hline $\begin{array}{l}\text { Composto } \\
\text { (esperado) }\end{array}$ & $\begin{array}{l}\mathrm{Fe} / \\
\mathrm{mg} \cdot \mathrm{L}^{-1}\end{array}$ & $\begin{array}{l}\mathrm{Sn} / \\
\mathrm{mg} \cdot \mathrm{L}^{-1}\end{array}$ & $\begin{array}{c}\% \mathrm{Fe} / \mathrm{SnO} \\
\text { (obtido) }\end{array}$ \\
\hline $0 \% \mathrm{Fe} / \mathrm{SnO}_{2}$ & 0,00 & 6313,5 & 0,00 \\
\hline $2,5 \% \mathrm{Fe} / \mathrm{SnO}_{2}$ & 4,10 & 4095,6 & 0,10 \\
\hline $2,5 \% \mathrm{Fe} / \mathrm{SnO}_{2}$ & 4,67 & 3109,9 & 0,15 \\
\hline $2,5 \% \mathrm{Fe} / \mathrm{SnO}_{2}$ & 12,99 & 6499,8 & 0,20 \\
\hline
\end{tabular}

\subsection{Microscopia Eletrônica de VARRedura}

A Figura 2 refere-se à micrografia do compósito de $\mathrm{SnO}_{2}$ puro e $\mathrm{SnO}_{2}$ dopado com $0,20 \%$ de ferro.
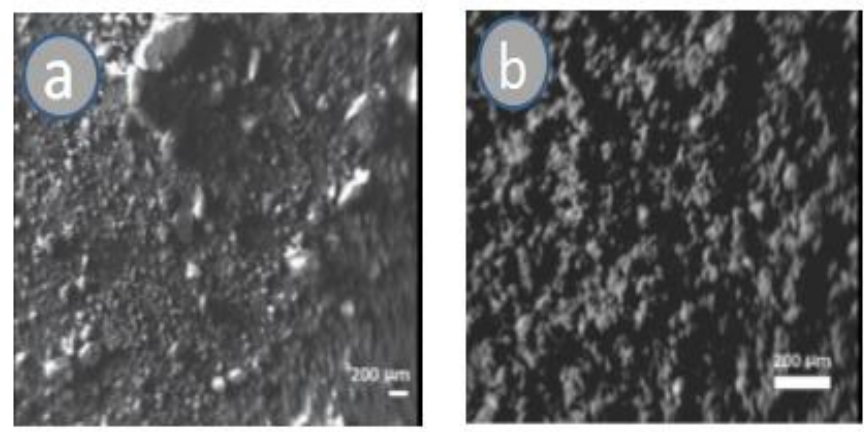

Figura 2 - (a) Micrografia da amostra $0 \% \mathrm{Fe} / \mathrm{SnO}_{2} \mathrm{e}$ (b) Micrografia da amostra $0,15 \% \mathrm{Fe} / \mathrm{SnO}_{2}$ Fonte - Próprio autor

A análise da Figura 2 permite observar um aglomerado de partículas próximas entre si, formando uma superfície granular com diâmetro de, aproximadamente, $19 \mathrm{~nm}$, calculado por meio da equação do Scherrer. Percebe-se, também, que a micrografia do dióxido de estanho puro mostrou pouca 
alteração em comparação com a amostra dopada com ferro. Resultado semelhante foi mostrado por Bose et al. (2005), que doparam o dióxido de estanho com ferro nas proporções de $2 \%$ e $4,5 \%$, utilizando do método de coprecipitação com hidróxido de amônio para avaliarem a eficiência dos materiais como sensores de gases propano e butano.

\subsection{DifRações de RAIOS $X$}

$\mathrm{Na}$ Figura 3 observam-se os difratogramas para os compostos de dióxido de estanho puro e dióxido de estanho modificado com ferro. Pela análise do mesmo, percebe-se uma grande semelhança do material puro em relação àqueles dopados com ferro.

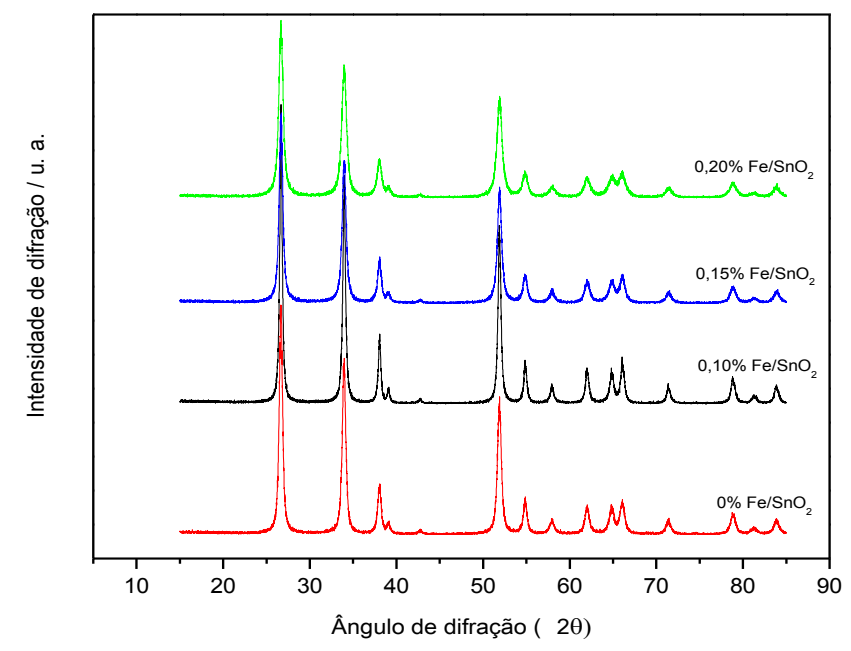

Figura 3 -1 Difratogramas de raios $\mathrm{X}$ para os materiais sintetizados

Fonte - Próprio autor

Os resultados demonstraram características da formação de dióxido estanho cristalino, syn cassiterita, conforme ficha catalográfica JCPDS 41-1445, Figura 4. Os testes de fluorescência de raios $X$ constatam a presença de ferro nos compostos e a semelhança nos difratogramas, No entanto, sugerem que os materiais podem estar dopados com o ferro. Os picos aparecem nos seguintes ângulos de difração $2 \theta: 26,63^{\circ} ; 33,73^{\circ}$; $37,94^{\circ}$ e $51,79^{\circ}$, com valores indexados em (110), (101), (200) e (211), respectivamente (ABDELKADER; NADJIA; AHMED, 2015).

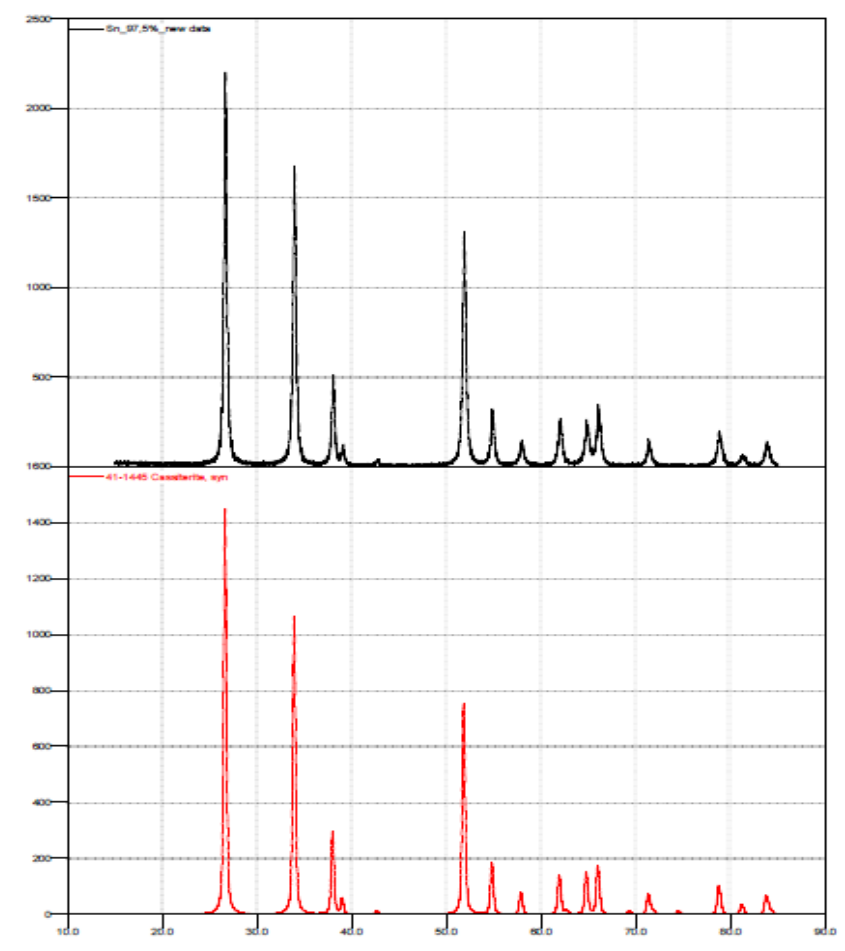

Figura 4 - Comparação da amostra da difração de raios $X$ do dióxido de estanho dopado com $0,15 \%$ de ferro com a ficha catalográfica 41-1445 Fonte - Próprio autor

\subsection{Reflectância Difusa no UV-VIS}

Relatos na literatura científica mostram que a dopagem do semicondutor pode contribuir para a diminuição do band gap. Xia et al. (2013) realizaram a dopagem da hematita com enxofre e constataram que, à medida que a concentração de enxofre aumentava, o valor de band gap diminuía. Na Figura 5 observa-se um comparativo das energias de band gap encontradas para as amostras de dióxido de estanho puro e dióxido de estanho dopadas com ferro em diferentes concentrações.

Nota-se, pela análise dos dados obtidos, Figura 5, que a dopagem das amostras de dióxido de estanho com ferro apresentou menor energia de band gap do que a amostra de dióxido de estanho puro. Constata-se também que, com exceção da amostra 0,20\% $\mathrm{Fe} / \mathrm{SnO}_{2}$, os valores de energia caíram à medida em que o teor de ferro nas amostras aumentou de 0,10\% 
para $0,15 \%$, conforme já constatado por Xia et al. (2013), que doparam hematita com enxofre.

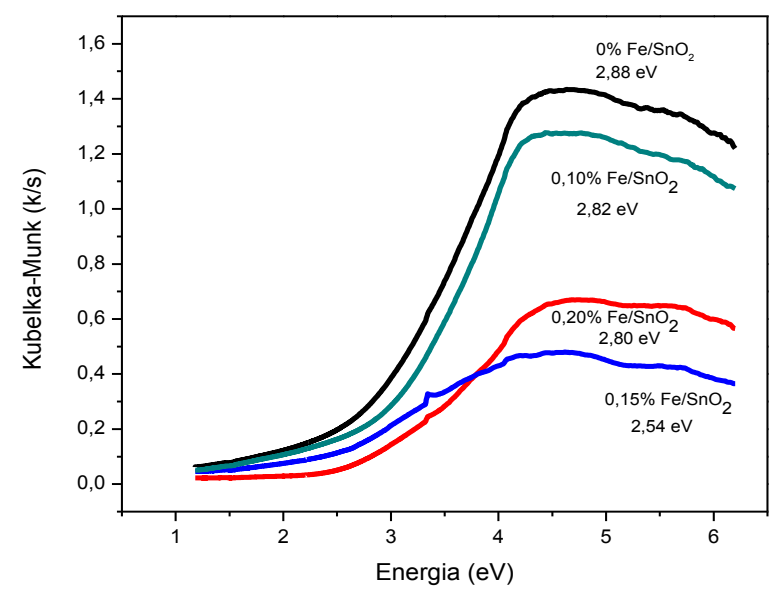

Figura 5 - Gráfico de band gap para as amostras de dióxido de estanho puro e dióxido de estanho dopadas com ferro em diferentes concentrações

Fonte - Próprio autor

\subsection{Decomposição de Peróxido de HIDROGÊNIO $\left(\mathrm{H}_{2} \mathrm{O}_{2}\right)$}

Observa-se, na Figura 6 em relação à Figura 7, que os volumes de $\mathrm{O}_{2}$ formados para os compostos puros $\mathrm{e}$ dopados se mantiveram praticamente constantes em relação à decomposição de peróxido de hidrogênio na presença de água e na presença de corante.

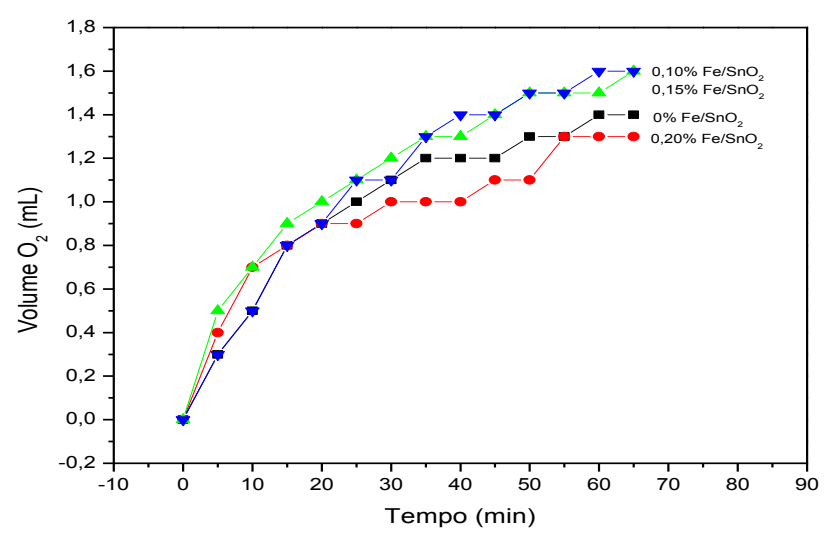

Figura 6 - Decomposição de $\mathrm{H}_{2} \mathrm{O}_{2}$ na presença de água e catalisador $\mathrm{SnO}_{2}$ e $\mathrm{SnO}_{2}$ dopado com ferro Fonte - Próprio autor

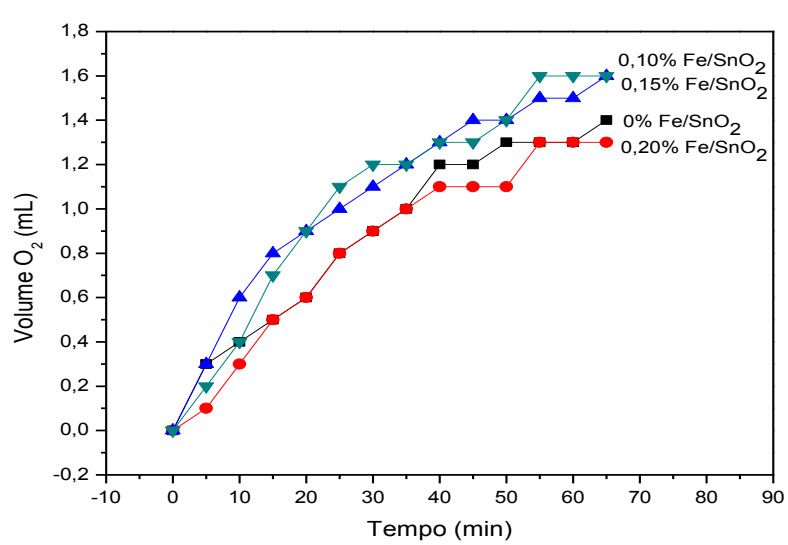

Figura 7 - Decomposição de $\mathrm{H}_{2} \mathrm{O}_{2}$ na presença de rodamina $\mathrm{B} 10$ ppm e catalisador $\mathrm{SnO}_{2}$ e $\mathrm{SnO}_{2}$ dopado com ferro Fonte - Próprio autor

Como não houve diferença significativa nos volumes de $\mathrm{O}_{2}$ gerados, sugere-se, então, neste caso, que a reação ocorra pelo sistema de vacância que segundo Moreira, Profeti e Profeti (2014), podendo auxiliar na catálise de intermediários reacionais e promover um aumento na atividade catalítica.

\subsection{INFLUÊNCIA DA Concentração do Corante}

O gráfico da Figura 8 refere-se ao resultado da fotocatálise variando a concentração do corante orgânico rodamina $B$, utilizando-se $40 \mathrm{mg}$ de catalisador e $0,001 \mathrm{~mL}$ de $\mathrm{H}_{2} \mathrm{O}_{2}$, sob agitação e temperatura de $25 \stackrel{\circ}{ } \mathrm{C}$.

Como se pode observar no gráfico de fotocatálise, o percentual de degradação de cor diminui consideravelmente à medida que se aumenta a concentração do corante. Com o aumento da concentração do corante e, por consequência, a coloração das soluções (e a sua absorbância), a radiação é cada vez mais absorvida pelas moléculas do mesmo, impedindo o contato da fonte de luz com o catalisador, diminuindo, assim, a eficiência da fotocatálise e, consequentemente, a remoção de cor da solução (DANESHVAR; SALARI; KHATAEE, 2003). 


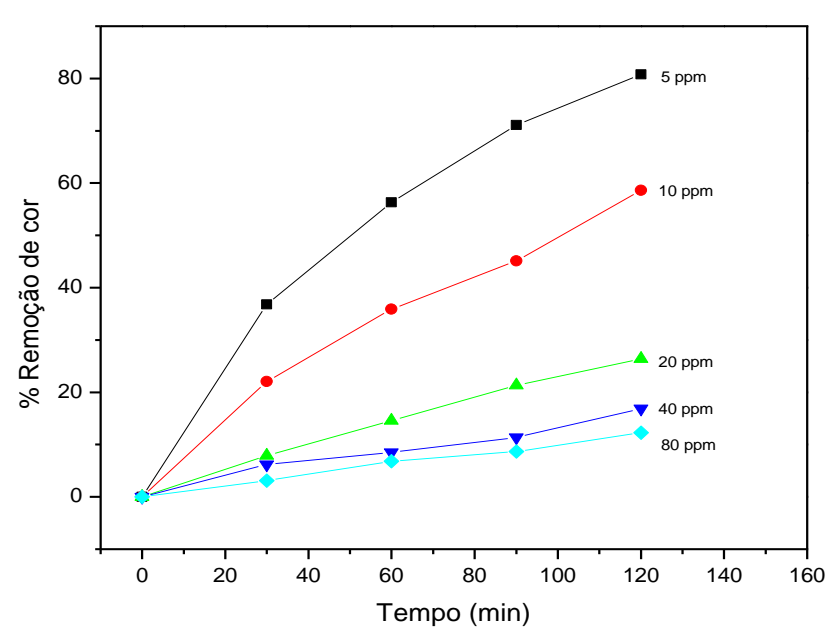

Figura 8 - Resultado da fotocatálise utilizando $40 \mathrm{mg}$ do catalisador de dióxido de estanho dopado com $1 \%$ de ferro para diferentes concentrações de rodamina $B$ Fonte - Próprio autor

Os testes foram realizados, então, com soluções do corante rodamina B 10 ppm, já que, para soluções muito concentradas, a eficiência da fotocatálise ficaria prejudicada.

\subsection{Influência da Quantidade de Peróxido DE HIDROGÊNIO}

Foi realizada a reação fotocatalítica utilizando-se 40 $\mathrm{mg}$ do catalisador $0,10 \% \mathrm{Fe} / \mathrm{SnO}_{2}$ na presença do corante orgânico rodamina B 10 ppm, variando-se a quantidade de peróxido de hidrogênio. Os resultados são mostrados na Figura 9.

Os resultados demonstram que as soluções que continham a maior concentração de peróxido de hidrogênio apresentaram maior remoção de cor em um menor intervalo de tempo. De acordo com a Figura 9, em apenas 30 minutos de reação, a solução que continha $0,2 \mathrm{~mL}$ de $\mathrm{H}_{2} \mathrm{O}_{2}$ removeu $87 \%$ de cor, chegando a, aproximadamente, $100 \%$ de remoção ao final de 120 minutos, ao passo que as soluções que continham $0,01 \mathrm{~mL}$ e $0,001 \mathrm{~mL}$ de peróxido removeram aproximadamente $90 \%$ e $60 \%$, respectivamente, ao final de 120 minutos.

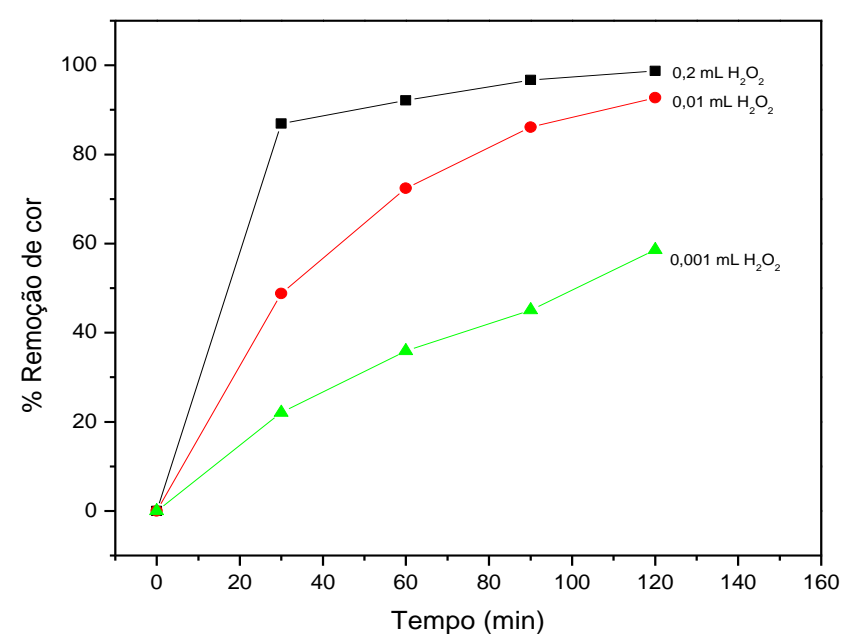

Figura 9 - Variação da quantidade de peróxido de hidrogênio

Fonte - Próprio autor

Os testes foram realizados com o volume de $0,001 \mathrm{~mL}$ de peróxido de hidrogênio, pois, em quantidades maiores, seria dificultada a análise da eficiência do fotocatalisador.

Conhecendo essas condições, foram realizados novos testes, variando o catalisador $\left(0 \% \mathrm{Fe} / \mathrm{SnO}_{2}, 0,10 \%\right.$ $\mathrm{Fe} / \mathrm{SnO}_{2} ; 0,15 \% \mathrm{Fe} / \mathrm{SnO}_{2}$ e $0,20 \% \mathrm{Fe} / \mathrm{SnO}_{2}$ ), com o objetivo de saber se a presença do dopante melhoraria a atividade fotocatalítica.

As reações foram monitoradas com medições no UVvis em temperatura de $25 \pm 1{ }^{\circ} \mathrm{C}$, sob agitação constante de $100 \mathrm{rpm}$, e monitorados nos tempos de $0,30,60,90$ e 120 minutos. Os experimentos fotocatalíticos foram realizados utilizando-se como reator uma caixa de madeira medindo $45 \mathrm{~cm} \mathrm{x} 40 \mathrm{~cm} \mathrm{x}$ $40 \mathrm{~cm}$ (largura $\times$ altura $\times$ profundidade), toda revestida com papel alumínio e uma lâmpada ultravioleta germicida de $15 \mathrm{~W}$ da marca Philips.

Observa-se que o material de dióxido de estanho puro apresentou menor remoção de cor em relação aos materiais dopados com $0,10 \%$ e $0,15 \%$ de ferro e maior remoção de cor em relação ao material com $0,20 \%$ de ferro, e que os materiais dopados com ferro se apresentaram mais eficientes quando dopados com menor teor de ferro. O dióxido de estanho puro apresentou $48 \%$ de remoção de cor, enquanto os 
materiais dopados apresentaram $58 \%, 57 \%$ e $43 \%$ de remoção de cor para os materiais contendo $0,10 \%$, $0,15 \%$ e $0,20 \%$ de ferro dopado, respectivamente (Figura 10).

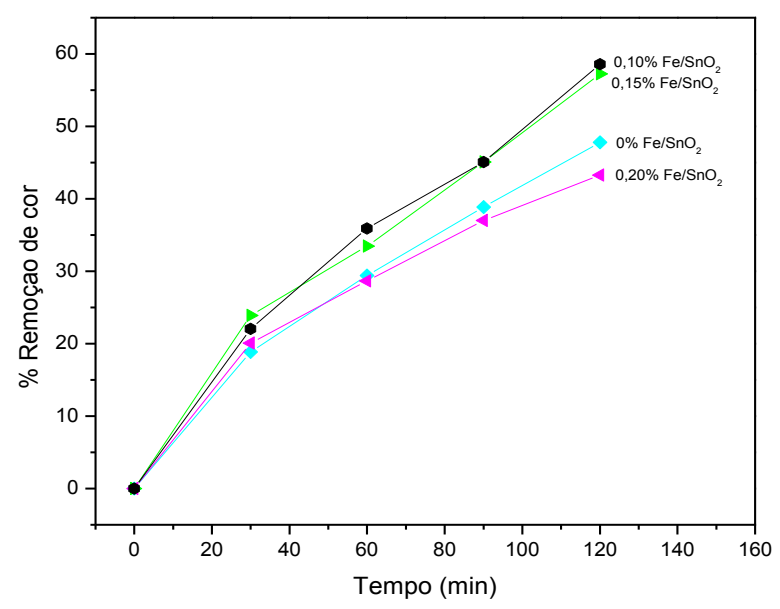

Figura 10 - Resultado dos testes fotocatalíticos na variação da porcentagem de ferro dopando o óxido de estanho, utilizando $40 \mathrm{mg}$ de catalisador

Fonte - Próprio autor

O dióxido de estanho puro apresenta energia de band gap maior do que os materiais dopados com $0,10 \%$ e $0,15 \%$ de ferro, e para o material com $0,20 \%$ de ferro pode estar havendo recombinação de elétrons da banda de valência para a banda de condução, observada pelo menor percentual de remoção de cor.

\section{CONCLUSÃo}

Realizou-se, neste trabalho, a dopagem do dióxido de estanho com ferro, obtendo-se os seguintes percentuais de material dopante 0,10\%, 0,15\% e $0,20 \%$. Foi constatado que, à medida que se aumentava a concentração do dopante, reduzia-se o tamanho das partículas do material. Constatou-se também uma redução no valor de band gap dos materiais quando se aumentava o teor de ferro nos mesmos, com exceção para o material 0,20\% $\mathrm{Fe} / \mathrm{SnO}_{2}$, que se mostrou contrário à tendência observada.
O uso de dióxido de estanho dopado com ferro como catalisador na fotocatálise heterogênea se mostrou com boa eficiência na remoção de cor de soluções contendo o corante orgânico rodamina B. Com 120 minutos de reação, usando $0,001 \mathrm{~mL}$ de peróxido de hidrogênio e $40 \mathrm{mg}$ de catalisador e irradiando a amostra com uma lâmpada ultravioleta germicida de $15 \mathrm{~W}$ de potência, foram obtidos $58 \%$ de remoção de cor com o material $0,10 \% \mathrm{Fe} / \mathrm{SnO}_{2}$ contra $48 \%$ do material puro, considerando as mesmas condições de reação.

Para o material $0,20 \% \mathrm{Fe} / \mathrm{SnO}_{2}$, a dopagem pode não ter ocorrido de forma efetiva, ocasionando um recobrimento do dióxido de estanho pelas partículas de ferro, evidenciado pelo valor de band gap encontrado e pelo menor percentual de remoção de cor $(43 \%)$, comparado aos demais catalisadores sintetizados.

\section{AgRAdecimentos}

Os autores agradecem à Fundação de Amparo à Pesquisa do estado de Minas Gerais - FAPEMIG, ao Conselho Nacional de Desenvolvimento Científico e Tecnológico - CNPq e à Universidade Federal de Lavras - UFLA pelo financiamento do trabalho.

Agradecem ao Centro de Análise e Prospecção Química - CAPQ/UFLA, ao Departamento de Ciência do Solo - DSC/UFLA e ao Prof. Luiz Carlos Alves de Oliveira - DQ/UFMG pelas análises realizadas. 


\section{REFERÊNCIAS}

ABDELKADER, E.; NADJIA, L.; AHMED, B.

Preparation and characterization of novel

$\mathrm{CuBi2O} / \mathrm{SnO} 2 \mathrm{p}-\mathrm{n}$ heterojunction with enhanced photocatalytic performance under UVA light irradiation.

Journal of King Saud University - Science, Algeria, v. 27, n. 1, p. 76-91, 2015.

BOSE, S. et al. Methane sensitivity of Fe-doped $\mathrm{SnO} 2$ thick films. Sensors and Actuators B, Kolkata, v. 105, p. 346-350, 2005.

CORNELL, R. M.; SCHWERTMANN, U. The iron oxides. $3^{\text {rd }}$ ed. New York: Weinheim-VHC, 2003. 664 p.

DANESHVAR, N.; SALARI, D.; KHATAEE, A. R. Photocatalytic degradation of azo dye acid red 14 in water: investigation of the effect of operational parameters. Journal of Photochemistry and Photobiology A: Chemistry, Lausanne, v. 157, n. 1, p. 111-116, 2003.

DEPARTAMENTO NACIONAL DE PRODUÇÃO MINERAL. Sumário mineral 2014. Disponível em: <http://www.dnpm.gov.br/>. Acesso em: 18 ago. 2015.

FU, Y.; VIRARAGHAVAN, T. Fungal decolorization of dye wastewaters: a review. Bioresource Technology, Essex, v. 79, n. 3, p. 251-262, 2001.
KHALED, A. et al. Treatment of artificial textile dye effluent containing Direct Yellow 12 by orange peel carbon. Desalination, Amsterdam, v. 238, n. 1/3, p. 210-232, 2009.

MOREIRA, T. F. M.; PROFETI, L. P. R.; PROFETI, D. Avaliação da atividade catalítica de catalisadores de $\mathrm{Pt} / \mathrm{Ti}$ com a adição de $\mathrm{CeO} 2$ para a reação de oxidação de etanol. Blucher Physics Proceedings, Alegre, v. 1, n. 2, p. 23-24, 2014.

OLIVEIRA, L. C. A. Óxidos de ferro e suas aplicações em processos catalíticos: uma revisão. Química Nova, São Paulo, v. 36, n. 1, p. 123-130, 2013.

SALGADO, B. C. B. et al. Descoloração de efluentes aquosos sintéticos e têxtil contendo corantes índigo e azo via processos Fenton e foto-assistidos (UV e UV/H2O2). Engenharia Sanitária e Ambiental, Rio de Janeiro, v. 14, n. 1, p. 1-8, 2009.

TEIXEIRA, A. P. C. et al. Iron: a versatile element to produce materials for environmental applications. Journal of the Brazilian Chemical Society, São Paulo, v. 23, n. 9, p. 1579-1593, 2012.

$X I A, C$. et al. Tuning the band gap of hematite $\alpha-$ $\mathrm{Fe} 2 \mathrm{O} 3$ by sulfur doping. Physics Letters $\mathrm{A}$, Amsterdam, v. 377, n. 31/33, p. 1943-1947, 2013. 